\title{
Origin of neointimal endothelium and $\alpha$-actin-positive smooth muscle cells in transplant arteriosclerosis
}

\author{
Jan-Luuk Hillebrands, ${ }^{1}$ Flip A. Klatter, ${ }^{1}$ Bart M.H. van den Hurk, ${ }^{1}$ Eliane R. Popa, ${ }^{2}$ \\ Paul Nieuwenhuis, ${ }^{1}$ and Jan Rozing ${ }^{1}$
}

${ }^{1}$ Department of Cell Biology, Immunology Section, and

${ }^{2}$ Department of Clinical Immunology, Faculty of Medical Sciences, University of Groningen, The Netherlands

Address correspondence to: J. Rozing, Department of Cell Biology, Immunology Section, Faculty of Medical Sciences, University of Groningen, A. Newsinglaan I, Building 3215, NL-9713 AV Groningen, The Netherlands.

Phone: 31-50-3632530; Fax: 31-50-3632512; E-mail: j.rozing@med.rug.nl.

Received for publication May 3, 2000, and accepted in revised form April 6, 2001.

\begin{abstract}
The development of transplant arteriosclerosis (TA) is today's most important problem in clinical organ transplantation. Histologically, TA is characterized by perivascular inflammation and progressive intimal thickening. Current thought on this process of vascular remodeling assumes that neointimal vascular smooth muscle (VSM) cells and endothelium in TA are graft-derived, holding that medial VSM cells proliferate and migrate into the subendothelial space in response to signals from inflammatory cells and damaged graft endothelium. Using MHC class I haplotype-specific immunohistochemical staining and single-cell PCR analyses, we show that the neointimal $\alpha$-actin-positive VSM cells in rat aortic or cardiac allografts are of recipient and not of donor origin. In aortic but not in cardiac allografts, recipient-derived endothelial cells (ECs) replaced donor endothelium. Cyclosporine treatment prevents neointima formation and preserves the vascular media in aortic allografts. Recipient-derived ECs do not replace graft endothelium after cyclosporine treatment. We propose that, although it progresses beyond the needs of functional repair, TA reflects the activity of a normal healing process that restores vascular wall function following allograft-induced immunological injury.
\end{abstract}

J. Clin. Invest. 107:1411-1422 (2001).

\section{Introduction}

The development of chronic transplant dysfunction (CTD) has become a limiting factor for long-term graft survival and is today's most important problem in clinical organ transplantation after the first perioperative year. To date, CTD cannot be prevented by current immunosuppressive protocols $(1,2)$. Depending on the type of organ transplanted (liver, kidney, heart, lung), the incidence of CTD 3 years after engraftment varies from 4 to $>50 \%$ (3-5). Irrespective of the organ grafted, graft vessels eventually develop so-called transplant arteriosclerosis (TA), which is, however, most prominent in cardiac allografts $(6,7)$. This vascular remodeling process consists of progressive concentric intimal thickening (intimal hyperplasia or neointima formation) coinciding with ongoing perivascular inflammation. TA has generally been accepted as the main cause of progressive deterioration in graft function. Pathogenesis of TA seems to be multifactorial, but precise mechanisms involved in the development of this remodeling process still remain obscure. Risk factors appear to include cold ischemia time and reperfusion injury, MHC disparity between donor and recipient, number of rejection episodes, and infection (especially by cytomegalovirus) $(2,6)$.

Current thought on the process of TA holds that in response to signals from inflammatory cells (perivasculi- tis) and activated or damaged graft endothelium donorderived medial vascular smooth muscle (VSM) cells of affected arteries start to proliferate and migrate from the media into the subendothelial space just beneath the endothelial cell (EC) layer (8-10). According to this concept, neointimal ECs and VSM cells in TA originate from graft tissue and are therefore donor-derived.

Since the early 1970 s, several groups have studied the origin of ECs (donor vs. recipient) after solid organ transplantation (kidney, heart, and lung) in humans. However, data both supporting (11-16) and discounting (17-20) repopulation of graft vessels by recipientderived ECs were reported.

Graft survival rates are significantly improved after solid organ transplantation since the introduction of new immunosuppressive drugs in the last two decades. From that time, not acute rejection but CTD and TA have become a major problem in clinical organ transplantation. To date, however, only a few studies have addressed the question of whether the neointimal VSM cells are indeed graft-derived (donor-derived), and again, results conflict (20-24). So far, no conclusive results have been described on the origin of ECs and VSM cells after solid organ transplantation.

From previous studies in our laboratory, using smallcaliber vascular grafts of synthetic biodegradable biomaterial, we know that such artificial grafts allow de 
novo formation of a new vessel wall $(25,26)$. In time, a neointima and neomedia were found to develop inside the lumen of the graft. Since the graft itself only consists of synthetic material, the cellular components forming the neomedia and the neointima, in this model, must be recipient-derived. Based on these observations we hypothesized that also after regular allogeneic organ transplantation a similar process of de novo vessel wall formation (vascular remodeling) will occur in the arteries of the graft, constituting cells originating from the recipient (27).

To test this hypothesis, we used two experimental transplant models. First, we used the allogeneic aorta transplant model in rats, which is a well-described and reproducible model to study TA (28). Second, we used a cardiac transplant model in which MHC-incompatible cardiac allografts are transplanted following intrathymic immune modulation and short-term immunosuppression (29). Cardiac allograft survival is significantly prolonged, but development of TA in the coronary artery (CA) tree cannot be prevented, resembling clinical outcome after cardiac transplantation (30). Using both transplant models we analyzed the origin of neointimal ECs and VSM cells, using MHC class I haplotype-specific immunohistochemistry and two independent PCR-based analyses $(31,32)$. Recipientand donor-specific PCR analyses were performed on $70-\mu \mathrm{m}$-thick tissue samples, microdissected neointimal cell clusters, and single-VSM-cell nuclei (aorta allografts), and on microdissected whole CAs and singleVSM-cell nuclei (cardiac allografts). Similar analyses were performed on aortic allografts that were $\gamma$-irradiated prior to transplantation, and grafts from recipients that were treated with cyclosporine (CsA).

Our results indicate that after allogeneic aorta transplantation neointimal ECs and VSM cells are of recipient and not of donor origin. CsA treatment prevented neointima formation and preserved the vascular media. After CsA treatment the ECs were still of donor origin and had not been replaced by recipient-derived cells. Although the neointimal VSM cells in cardiac allografts are of recipient origin, recipient-derived cells do not replace donor ECs.

Thus, in contrast to current thought, VSM cells constituting the hyperplastic neointima in aortic as well as cardiac allografts are of recipient and not of donor origin. EC replacement is not a general phenomenon after allogeneic organ transplantation and might be related to the severity of the initial damage of graft endothelium. We propose that TA is part of a normal healing process trying to restore function of the damaged vessel wall. Recipient-derived ECs and VSM cells are involved in this repair process, which, however, does not seem to be controlled adequately and eventually may lead to total occlusion of the vessels.

\section{Methods}

Animals. Specific pathogen-free Lewis (Lew, RT-11), Brown Norway (BN, RT-1 ${ }^{\mathrm{n}}$ ), Pibold Viral Glasco (PVG)
(RT-1 ${ }^{\mathrm{c}}$ ), and Albino Oxford (AO) (RT-1 $\left.{ }^{\mathrm{u}}\right)$ rats were obtained from Harlan (Zeist, The Netherlands). The rats were 7-10 weeks of age and were used for aorta and cardiac transplantation. All transplantations were performed from female donor to male recipient rats. Animals were maintained under clean conventional conditions and fed standard rat chow and acidified water ad libitum. All animals received care in compliance with NIH principles of laboratory animal care and the Dutch Law on Experimental Animal Care.

Aorta transplantation. Aortic allografts $(10-12 \mathrm{~mm})$ were transplanted orthotopically as described previously (28). Total ischemic time was consistently less than $30 \mathrm{~min}$ utes. Transplantations were performed in the following MHC-incompatible strain combinations: PVG to AO, $\mathrm{BN}$ to Lew, and Lew to BN. Isograft controls consisted of aortic grafts transplanted from $\mathrm{AO}$ to $\mathrm{AO}$ and $\mathrm{BN}$ to $\mathrm{BN}$ rats. Grafts were removed at autopsy 1 month (BN to Lew and Lew to $\mathrm{BN}$ ) or 3 months (PVG to AO and isograft controls) after transplantation and processed for histological evaluation or microdissection.

Cardiac transplantation. Cardiac allografting was performed from female PVG to male AO recipient rats. To prevent acute rejection, recipient rats were intrathymically immune-modulated as described elsewhere (29). Immediately after cardiac transplantation (day 0$), 1 \mathrm{ml}$ rabbit anti-rat lymphocyte serum (Accurate Chemical \& Scientific Corp., Westbury, New York, USA) was injected intraperitoneally. CsA (Sandoz Pharma AG, Basel, Switzerland) was injected intramuscularly on days 1,2 , and 3 after transplantation $(15 \mathrm{mg} / \mathrm{kg})$. Cardiac allografts thus transplanted show significantly prolonged graft survival but eventually develop TA indicative of CTD (30).

Treatment groups. Aortic allografting was performed from female PVG donor to male AO recipient rats. One group was left untreated $(n=4)$, whereas in the other group aortic allografts were ex vivo $50 \mathrm{~Gy} \gamma$-irradiated $\left({ }^{137} \mathrm{Cs}\right.$, IBL 673; CIS Bio International Gif-Sur-Yvette, France) prior to transplantation in order to prevent proliferation and migration of donor-derived medial VSM cells $(n=3)$. Three AO isograft controls were performed $(n=3)$. To study the effect of CsA treatment on the development of TA, another set of aorta transplantations was performed in the female Lew to male BN combination. Recipient rats received either no treatment $(n=5)$ or CsA (Sandoz Pharma AG) at 5 $\mathrm{mg} / \mathrm{kg} / \mathrm{d}(n=5)$ or $10 \mathrm{mg} / \mathrm{kg} / \mathrm{d}(n=4)$ for 28 days. These concentrations were shown to reduce intimal hyperplasia and preserve medial nuclear density after allogeneic aorta transplantation in rats (33). CsA was administered as a liquid in olive oil by intramuscular injections. BN to Lew allografts $(n=3)$ and $\mathrm{BN}$ isografts $(n=5)$ served as control groups.

To analyze TA in cardiac allografts, three femalederived PVG grafts were transplanted into male $\mathrm{AO}$ recipient rats followed by intrathymic immune modulation as described above $(n=3)$. Grafts were harvested 530 days (19 months) after transplantation and processed for histological analysis and microdissection. 
CsA blood levels. Twenty-four-hour trough whole blood CsA levels were determined 2 and 4 weeks after aortic transplantation. Blood was analyzed using the Emit 2000 cyclosporine-specific assay (Dade Behring, Marburg, Germany).

Immunohistochemical analyses. At the time of sacrifice, the explanted aortic and cardiac grafts were either fixed in Bouin's fixative and embedded in paraffin or immediately frozen in liquid nitrogen and stored at $-80^{\circ} \mathrm{C}$ for cryostat sections. For evaluation of vascular changes, paraffin cross sections $(7 \mu \mathrm{m})$ from the center of the grafts were prepared, and double staining was performed for elastin (Lawson solution; Klinipath, Duiven, The Netherlands) and $\alpha$-actin to detect neointimal VSM cells in arteriosclerotic lesions. Briefly, $\alpha$-actin-positive intimal cells were detected by an indirect immunoperoxidase technique using $\mathrm{mAb}$ asm-1 directed against VSM cell $\alpha$-actin isoform $(34,35)$ (Roche Molecular Biochemicals, Almere, The Netherlands). Incubation with the primary asm-1 antibody was followed by incubation with a second-step horseradish peroxidase-conjugated rabbit anti-mouse antibody (DAKO A/S, Glostrup, Denmark). Subsequently, chromogen 3-amino-9-ethyl carbazole was applied, followed by counterstaining with Mayer's hematoxylin. Sections were coverslipped with Kaiser's glycerol gelatin (Merck, Amsterdam, The Netherlands).

To detect MHC class I expression on ECs and graftinfiltrating inflammatory cells the following mAb's were used: OX18 (pan-class I) (36), OX27 (PVG [RT-1c] and $\mathrm{BN}\left[\mathrm{RT}-1^{\mathrm{n}}\right]$ class I) (37), and U9F4 (AO [RT-1 $\left.{ }^{\mathrm{u}}\right]$ class I) (38). To detect ECs and infiltrating macrophages, mAb's RECA-1 (39) and ED1 (40) were used, respectively. MHC class I, EC, and macrophage staining was performed on $7-\mu \mathrm{m}$ cryostat sections using the DAKO EnVision staining kit (DAKO A/S). Sections were counterstained with Mayer's hematoxylin and coverslipped with Depex mounting medium (BDH Laboratory Supplies, Poole, United Kingdom).

Quantitation of TA. After histological staining of tissue sections for elastin and $\alpha$-actin, presence of TA was quantitated using a computerized morphometric analysis system (QWin Software; Leica Microsystems B.V., Rijswijk, The Netherlands). Total surface area of arteriosclerotic lesions (neointima) was calculated and expressed as $\mu \mathrm{m}^{2}$.

Microdissection of neointimal tissue. Microdissection of neointimal tissue was performed on $\alpha$-actin-stained 7$\mu \mathrm{m}$ cryostat sections (taken from the center of the graft) from aortic as well as cardiac allografts. $\alpha$-Actin staining ensured positive identification of neointimal VSM cells in aortic allografts and affected CAs in cardiac allografts. After counterstaining with Mayer's hematoxylin, tissue sections were placed in PBS and stored overnight at $4{ }^{\circ} \mathrm{C}$. Subsequently, microdissection was performed using a micromanipulator (Leica Microsystems B.V.) from neointimal lesions containing large numbers of $\alpha$-actin-positive VSM cells. Cell clusters consisting of 20-30 cells were microdissected from neointimal lesions in aortic allografts as well as in CAs. To prevent potential contamination of the cell clusters with infiltrating mononuclear cells, single nuclei from $\alpha$-actin-positive neointimal cells in aortic allografts and CAs were microdissected as well. For single cell picking, nuclei were randomly selected among $\alpha$-actin-positive cells having an easily visible nucleus surrounded by $\alpha$-actin-positively stained cytoplasm. Microdissected cell clusters and isolated single nuclei were directly transferred into PCR reaction tubes containing $20 \mu \mathrm{l}$ Milli-Q water (Millipore B.V., Etten-Leur, The Netherlands, USA) and stored at $-20^{\circ} \mathrm{C}$ until PCR analysis.

PCR analyses. The first PCR that was used to analyze the origin of neointimal cell types after aortic and cardiac allografting was based on polymorphic regions present in the Tap2 gene encoding a subunit of a peptide transporter involved in loading of MHC class I molecules with peptides (31). Because the Tap2 gene is located within the MHC, all MHC haplotypes are associated with a specific Tap2 allele. To determine the Tap2 genotype of isolated DNA, a PCR procedure developed by Joly et al. was used based on differences in restriction sites found in the sequences of the Tap2 cDNAs (31). Oligonucleotides used were as follows: $3605^{\prime}$-ccgggctctagaTGCAGACCGTGAGAAGCTTTG-3' and 361 5' ' $^{\prime}$ ccgggcgaattcCTGCACACCGACGTTCAGAAT- $3^{\prime}$ (sequences in lower case do not correspond to Tap2 sequences but were introduced for cloning of the various alleles by PCR). Since microdissected cell clusters and single nuclei did not contain sufficient DNA to give a positive signal (not shown), the Tap2 PCR was performed on $70-\mu \mathrm{m}$-thick tissue samples obtained from aortic allografts. In addition, microdissected CAs showing severe TA from one graft were pooled ( 10-20 CAs) to get sufficient template DNA to perform the Tap2 PCR. After amplification, $10 \mu \mathrm{l}$ of the $\mathrm{PCR}$ reaction mixture was analyzed on a GelStar (BMA, Rockland, Maine, USA) $2 \%$ agarose gel. Sizes of the PCR products of the different rat strains were: Lewis, 380 bp; BN, 360 bp; PVG, $340 \mathrm{bp}$; and $\mathrm{AO}, 360 \mathrm{bp}$.

Since all transplantations were performed in female (donor) to male (recipient) combinations, we could also use sex markers as indicators for cellular origin. Therefore, a nested PCR procedure was developed that specifically enabled identification of a Y chromosome-associated DNA sequence (European Molecular Biology Laboratory [EMBL]/GenBank data libraries accession no. X80155) (41) at the single-cell level and thereby the (male) origin of cells (described in detail elsewhere; ref. 32). The following Y chromosome-specific oligonucleotides were used: first round $5^{\prime}$-CAGGCTGGAAAGGCTTGTAG-3' (forward) and $5^{\prime}$-CCCATGTTTGGTCCACATAG-3' (reverse), and second round $5^{\prime}$-GCTGGTGATTTGCAGAGTGA-3' (forward) and 5'-GAATGTTCGATTCCGACTGG-3' (reverse). The first and second round of PCR amplification resulted in 549-bp and 128-bp DNA fragments, respectively. After amplification, $10 \mu$ l of the 2 nd round reaction mixture was analyzed on a GelStar (BMA) 2\% agarose gel. All amplifications were carried out using an Amplitron II 


\section{Figure 1}

(a and $\mathbf{b}$ ) Development ofTA (expressed as $\mu \mathrm{m}^{2}$ ) after allogeneic aorta transplantation. (a) Nonirradiated as well as 50 Gy $\gamma$-irradiated PVG aortic allografts developed significant TA 3 months after transplantation into $\mathrm{AO}$ recipient rats. ${ }^{A} P<0.05$ vs. AO isografts, Mann-Whitney $U$ test. NS, not significant. (b) CsA treatment $(5 \mathrm{mg} / \mathrm{kg} / \mathrm{d}$ and 10 $\mathrm{mg} / \mathrm{kg} / \mathrm{d}$ ) for 28 days prevented development of TA after aorta transplantation in the Lew to BN strain combination. ${ }^{A} P<0.05,{ }^{B} P<0.01$ vs. untreated recipients, Mann-Whitney $U$ test. (c, e, and $\mathbf{f}$ ) Double staining for VSM cells $(\alpha$-actin) and elastin (Lawson). Nontreated allograft is shown in $\mathbf{c}$. Note the absence of $\alpha$-actin-positive VSM cells in the vascular media (c). Neointimal lesions in nontreated allografts contained considerable numbers of ED1 ${ }^{+}$ macrophages (d). Treatment with $5 \mathrm{mg} / \mathrm{kg} / \mathrm{d} \mathrm{CsA}(\mathbf{e})$ and $10 \mathrm{mg} / \mathrm{kg} / \mathrm{d}$ CsA (f) prevented development of TA 1 month after transplantation. VSM cells were abundantly present in the vascular media. No adventitial inflammation was observed. a, adventitia; lu, lumen; m, media; iel, internal elastic lamina; ni, neointima. Original magnification: $\times 400$.

Thermolyne thermocycler (Barnstead/Thermolyne, Dubuque, Iowa, USA).

Restriction enzyme analysis. Since Tap2 PCR fragments derived from Lew DNA bear a HindIII restriction site and BN-derived DNA fragments do not, further discrimination between Lew- and BN-derived DNA could be made by HindIII restriction analysis. After Tap2 PCR analysis, $5 \mu \mathrm{l}$ PCR product was added to $5 \mu \mathrm{l}$ restriction mix containing $5 \mathrm{U}$ HindIII (Life Technologies B.V., Breda, The Netherlands). After incubation for 1 hour at $37^{\circ} \mathrm{C}$, DNA samples were analyzed by $2 \%$ agarose gel electrophoresis. Lew-derived DNA was cut into two fragments (276 and $104 \mathrm{bp}$ ), whereas BN-derived DNA remained uncut.

Since PVG- and AO-derived DNA both lack the HindIII restriction site in their Tap2 sequence, discrimination could only be made by difference in size of the PCR products (340 and $360 \mathrm{bp}$ respectively). Therefore, those PCR products were electrophoresed on a $12 \%$ polyacrylamide gel using a Mini-PROTEAN II Bio-Rad system (Bio-Rad Laboratories B.V., Veenendaal, The Netherlands). After electrophoresis the gel was soaked in ethidium bromide-containing TBE buffer to visualize PCR products.

Statistical analysis. To analyze differences in surface area of arteriosclerotic lesions for statistical significance, a Mann-Whitney $U$ test was performed using SPSS 7.5.2 for Windows (SPSS, Chicago, Illinois, USA). Differences were considered to be statistically significant when $P$ values were less than 0.05 .

\section{Results}

Effect of irradiation and CsA treatment on TA. Transplantation of fully MHC-mismatched aortic allografts in the PVG to AO rat strain combination resulted in the
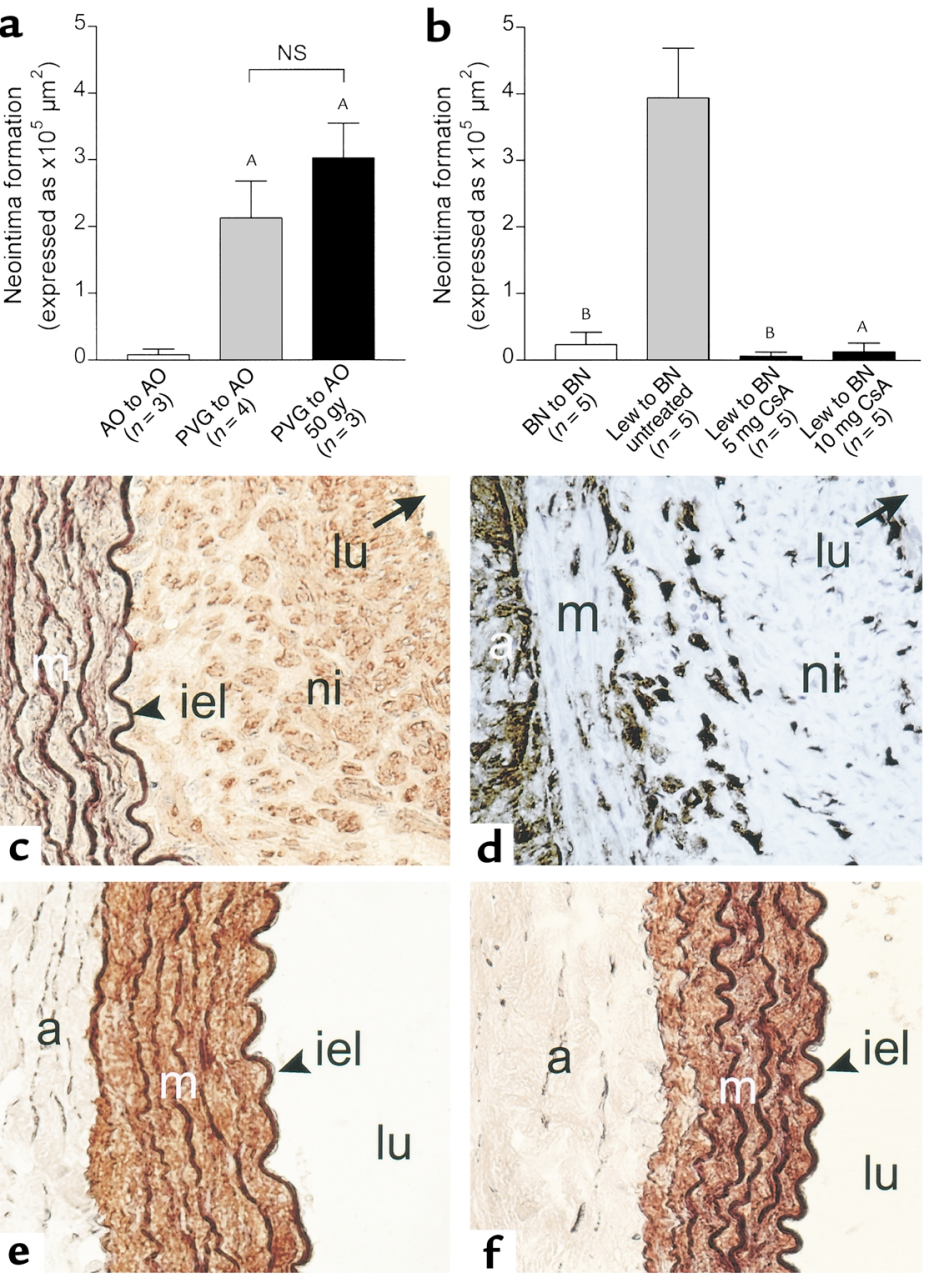

development of severe TA. Whereas AO isografts were unaffected or only slightly affected, allografts showed significant $(P<0.05)$ neointima formation 3 months after transplantation, indicating that TA in this model is mainly caused by an alloantigen-driven process (Figure 1a). We then asked whether aortic allografts, which contain medial VSM cells that have lost migratory and proliferative capacities, still lead to development of neointimal lesions after transplantation. To answer this question, PVG aortic allografts were ex vivo $50 \mathrm{~Gy}$ $\gamma$-irradiated prior to engraftment into $\mathrm{AO}$ recipients. As shown in Figure 1a $\gamma$-irradiated allografts developed neointimal lesions to the same extent as nonirradiated allografts, indicating that graft medial VSM cells probably do not contribute to the process of TA.

Subsequently, the influence of immunosuppressive therapy on the development of TA after allogeneic aorta transplantation was analyzed. Aortic grafts were transplanted in the Lew to BN combination. From previous studies it became obvious that severe TA develops within 4 weeks after transplantation in this strain combination (Figure 1b) (42). Recipient rats received either no treatment or CsA at $5 \mathrm{mg} / \mathrm{kg} / \mathrm{d}$ or $10 \mathrm{mg} / \mathrm{kg} / \mathrm{d}$ for 28 days. After 14 and 28 days, 24 hour trough whole blood CsA levels were determined 
in three animals from either group. No differences were observed between the 14- and 28-day time points, and therefore data from both time points were pooled. Animals treated with $5 \mathrm{mg} / \mathrm{kg} / \mathrm{d}$ and 10 $\mathrm{mg} / \mathrm{kg} / \mathrm{d}$ CsA had mean trough levels of $1016 \pm 268$ $\mathrm{ng} / \mathrm{ml}$ and $2383 \pm 327 \mathrm{ng} / \mathrm{ml}$, respectively. The nontreated group had trough levels below detection level $(<25 \mathrm{ng} / \mathrm{ml})$. Treatment with $5 \mathrm{mg} / \mathrm{kg} / \mathrm{d}$ and 10 $\mathrm{mg} / \mathrm{kg} / \mathrm{d}$ both resulted in complete inhibition of neointima formation 28 days after transplantation $(P<0.01$ and $P<0.05$, respectively) (Figure $1 \mathrm{~b}$ ). After CsA treatment, no differences were observed compared with the isograft (BN to BN) controls.

Representative micrographs of vascular wall morphology are shown in Figures 1, c-f. The nontreated group displayed severe neointima formation with presence of large numbers of $\alpha$-actin-positive VSM cells (Figure 1c). The media had become acellular, and medial $\alpha$-actin-positive VSM cells had disappeared. In addition, graft-infiltrating ED1 ${ }^{+}$macrophages were present in both the adventitia and the neointima (Figure 1d).
After CsA treatment, however, morphology appeared to be normal (no neointima formation) in both treatment groups and was similar to nontransplanted aortic tissue. Grafts from CsA-treated recipients were characterized by a high nuclear density in the media, which appeared to be $\alpha$-actin-positive VSM cells (Figure 1, e and f).

Origin of ECs in nontreated and CsA-treated aorta recipients. To analyze the origin (donor vs. recipient) of ECs after allogeneic aorta transplantation, MHC class I haplotype-specific immunohistochemistry was performed (Figure 2). PVG allografts transplanted in $\mathrm{AO}$ recipient rats showed severe neointima formation 3 months after transplantation (Figure 1a). Presence of ECs was confirmed by positive staining using mAb RECA-1 (not shown). Serial tissue sections were stained using mAb's OX18, OX27, and U9F4. Neointimal ECs express MHC class I antigens as indicated by intense staining with mAb OX18 (pan-class I), whereas neointimal VSM cells do not express MHC class I antigens sufficiently to allow detection by this staining (Figure 2a). Note the absence of nuclei in the media and the swollen appear-
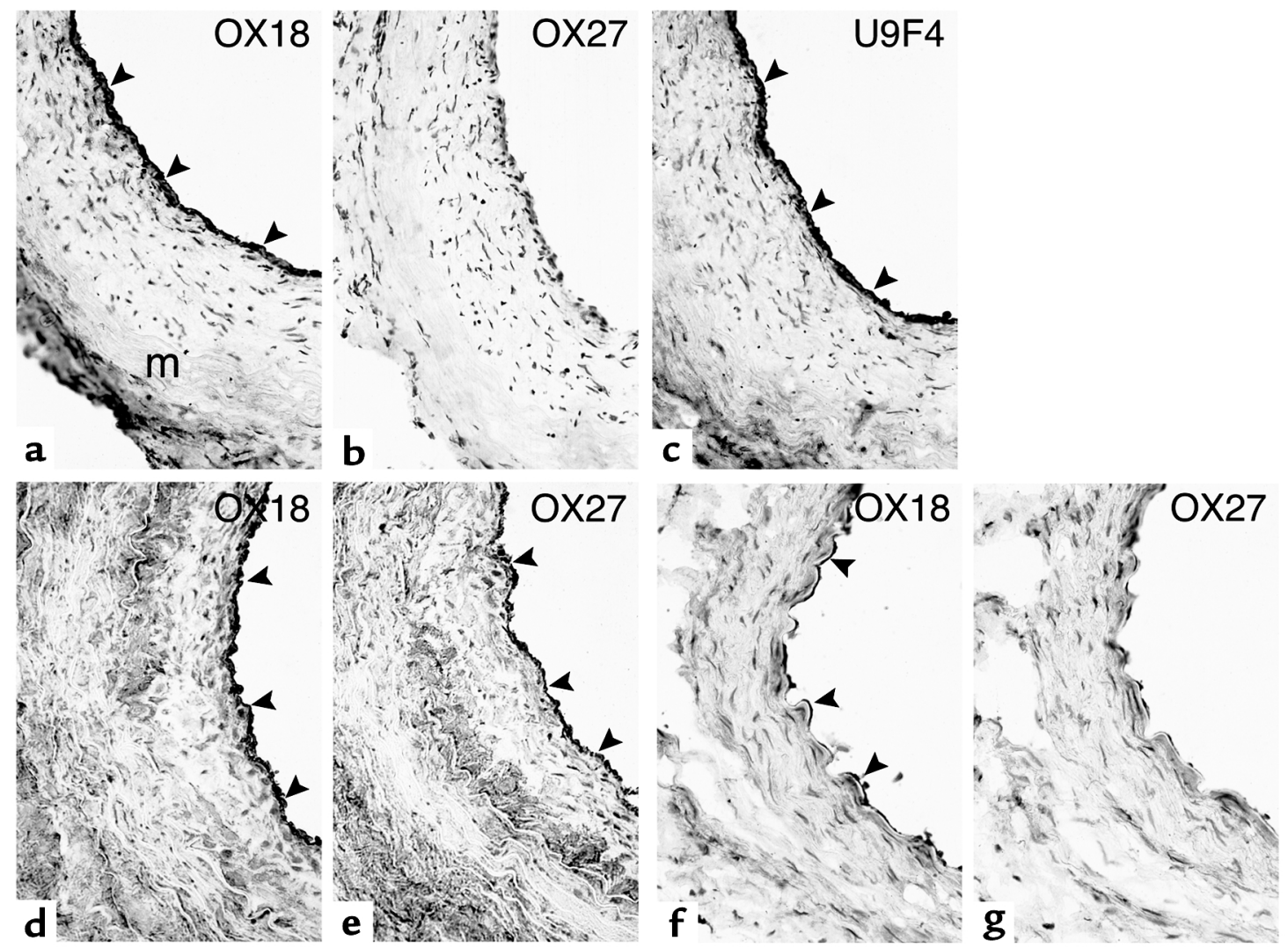

Figure 2

Neointimal ECs in aortic allografts are of recipient origin. Immunohistochemical staining using MHC class I haplotype-specific mAb's was performed to determine the origin (donor vs. recipient) of neointimal ECs after allogeneic aorta transplantation. PVG allografts transplanted in AO recipients showed severe TA. (a) MHC class I expression on ECs (OX18-positive). Note the absence of VSM cells in the media $(\mathrm{m})$. Donor endothelium had disappeared (OX27-negative) (b) and had been replaced by recipient-derived ECs (U9F4-positive) (c). Lew allografts transplanted into BN recipient rats also showed severe TA. (d) MHC class I expression on ECs (OX18-positive). (e) Donor endothelium had been replaced by recipient-derived ECs (OX27-positive). After CsA treatment, no neointima formation was observed 1 month after transplantation. (f) ECs covering the internal elastic lamina expressed MHC class I antigens (OX18-positive). However, ECs were OX27 (recipient class I)-negative (g), indicating that after CsA treatment EC replacement does not occur. Arrowheads indicate positively stained ECs. Original magnification: $\times 400$. 


\section{Figure 3}

Neointimal ECs in cardiac allografts are of donor origin. Immunohistochemical staining was performed on nontransplanted AO cardiac tissue (a-e) and PVG allografts $(\mathbf{f}-\mathbf{j})$. (a) Medial VSM cells are $\alpha$-actin-positive in CAs in normal, nontransplanted $\mathrm{AO}$ cardiac tissue. (b) ECs are covering the internal elastic lamina as indicated by positive RECA-1 staining. (c) MHC class I expression on ECs was confirmed by positive staining using OX18. (d) U9F4 is AO MHC class I haplotype-specific and recognizes AO-derived ECs. (e) OX27 does not recognize $A O$-derived ECs. $P V G$ cardiac allografts transplanted in $A O$ recipients showed severe TA 530 days after transplantation. The vascular lumen is obliterated as a result of neointima formation. (f) Neointimal tissue predominantly consists of $\alpha$-actin-positive VSM cells. (g) Neointima is covered by RECA-1-positive ECs. Note the swollen and activated appearance of the neointimal ECs. (h) MHC class I expression on ECs was confirmed by positive staining using OX18. (i) Neointimal ECs are U9F4-negative, indicating donor origin. (j) Positive OX27 staining confirmed donor origin of neointimal ECs in CAs with severe TA. Arrowheads indicate positively stained ECs. $m$, media; ni, neointima. Original magnification: $\times 400$.

ance of the ECs. Staining with mAb OX27 (donor type) was negative (Figure $2 \mathrm{~b}$ ), whereas mAb U9F4 (recipient type) clearly showed positive staining of ECs (Figure 2c), indicating that donor ECs had been replaced by recipient-derived ECs. Similar results were obtained after haplotype-specific MHC class I staining of PVG allografts that were 50 Gy $\gamma$-irradiated prior to transplantation into $\mathrm{AO}$ recipient rats (not shown).

To further analyze whether EC replacement had also taken place after CsA treatment, serial tissue sections from aortic grafts transplanted in the Lew to BN strain combination were stained using mAb's OX18 (pan-class I) and OX27 (recipient type). Again, presence of ECs was confirmed by positive staining using $\mathrm{mAb}$ RECA-1 (not shown). Neointimal ECs from untreated animals showed abundant MHC class I expression as indicated by positive OX18 staining (Figure 2d). Also, in this strain combination, donor endothelium had been replaced by recipient-derived ECs as indicated by positive OX27 staining. MHC class I staining of aortic allografts transplanted in the reciprocal BN to Lew strain combination confirmed these results (not shown). After CsA treatment, however, donor endothelium was still covering the internal elastic lamina and had not been replaced by recipient-derived ECs. ECs express MHC class I (positive staining using mAb OX18) (Figure 2f) but lack positive staining using the recipient specific $\mathrm{mAb}$ OX27 (Figure 2g).

Origin of ECs in cardiac allografts. Cardiac transplantation following intrathymic immune modulation resulted in development of severe TA in the CAs (30). To study whether EC replacement by recipient-derived ECs had also taken place in these cardiac allografts, recipient and donor MHC class I-specific staining was performed. As control tissue, normal cardiac AO-derived tissue was used. Representative micrographs are shown in Figure 3. Results of normal AO cardiac tissue and PVG allografts are depicted in Figure 3, a-e and $\mathrm{f}-\mathrm{j}$, respectively.
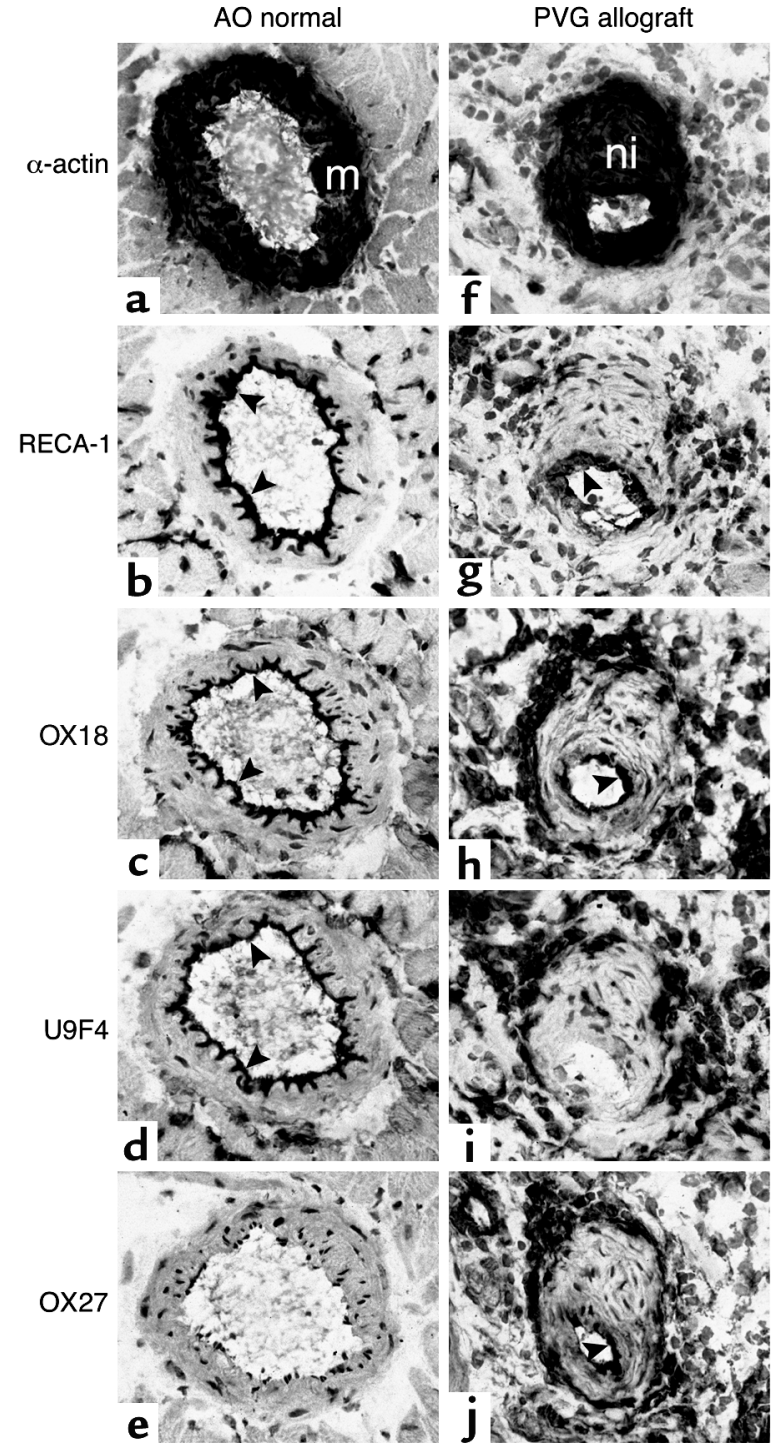

VSM cell $\alpha$-actin staining (Figure 3f) confirmed presence of severe neointima formation and luminal narrowing in the CAs in PVG allografts explanted 530 days after transplantation. RECA-1 staining showed presence of ECs (Figure 3, b and g). Note the swollen and activated appearance of ECs covering the neointima in the PVG allograft. OX18 (pan-class I) staining confirmed presence of MHC class I expression by ECs in normal cardiac tissue and PVG allografts (Figure 3, c and h). Neointima-infiltrating leukocytes were virtually absent in the arteriosclerotic lesions. However, perivascular mononuclear cell infiltrates (MHC class I-positive) were present in the PVG allografts. Staining with recipient-specific mAb U9F4 showed positive staining of the mononuclear cell infiltrates (which, as expected, are recipient-derived) (Figure $3 i$ ). However, the neointimal ECs in the PVG allografts are negative, suggesting that, in contrast to aortic allografts, recipient ECs have not replaced donor endothelium in CAs with severe TA. This was confirmed by positive staining of neointimal ECs with the donor-specific mAb OX27 
(Figure 3j). Similar findings were obtained in CAs in PVG allografts showing only mild TA as well as CAs showing no TA at all (not shown).

Tap2 PCR analysis of aortic and cardiac tissue. Since neointimal VSM cells do not express MHC class I antigens sufficiently to allow MHC class I-specific immunohistochemistry to study the origin of neointimal VSM cells in aortic and cardiac allografts, another (PCR-based) approach was followed to define the origin of $\alpha$-actin-positive neointimal cells.

The first PCR that was used to analyze the origin of neointimal cell types after aortic and cardiac allografting was based on polymorphic regions in the Tap2 gene. Because of the relatively low sensitivity of the Tap2 PCR, analysis was performed on $70-\mu \mathrm{m}$-thick tissue samples of aortic allografts transplanted in the BN to Lew, Lew to BN, and Lew to BN + CsA (5 and 10 $\mathrm{mg} / \mathrm{kg} / \mathrm{d}$ CsA) combinations. Three individual grafts from either group were included, and of each graft four $70-\mu \mathrm{m}$-thick tissue samples were analyzed. Nontransplanted BN and Lew aortic tissue served as controls for specificity of this Tap2 PCR. As shown in Figure 4a, control BN and Lew DNA resulted in DNA fragments of $360 \mathrm{bp}$ and $380 \mathrm{bp}$, respectively. Restriction analysis with HindIII showed cleavage of the Lew-derived 380bp fragments into 276-bp and 104-bp fragments, whereas the BN-derived 360-bp fragments remained uncut, thereby proving the specificity of this Tap2 PCR.
Subsequently, this PCR was applied to tissue samples obtained from grafts transplanted from BN donor to Lew recipient rats. Tap2 PCR followed by HindIII restriction showed cleavage of the DNA fragments into two fragments, indicating Lew (recipient) origin of the majority of the DNA present in these samples. This was confirmed by analysis of tissue obtained from grafts transplanted in the reciprocal combination (Lew to BN). After HindIII restriction the DNA fragments remained uncut, indicating $\mathrm{BN}$ (recipient) origin of the DNA present in these samples. Finally, the same analysis was performed on tissue from Lew grafts transplanted into $\mathrm{BN}$ recipient rats followed by CsA treatment $(5 \mathrm{mg} / \mathrm{kg} / \mathrm{d})$ for 28 days. HindIII restriction showed cleavage of the DNA fragments into two fragments, indicating Lew (donor) origin of the majority of the DNA after CsA treatment (Figure 4a). Similar results were obtained from analysis of aortic allografts after treatment with $10 \mathrm{mg} / \mathrm{kg} / \mathrm{d}$ CsA (not shown). These results suggest that both neointimal ECs and VSM cells are recipient-derived in aortic allografts.

To study whether the same holds true for neointimal cells in cardiac allografts, Tap2 PCR analysis was performed on microdissected CAs showing severe TA. To obtain sufficient DNA, microdissected CAs from one graft were pooled prior to PCR analysis. Since PVGand AO-derived DNA both lack the HindIII restriction site in their Tap2 sequence, discrimination could only
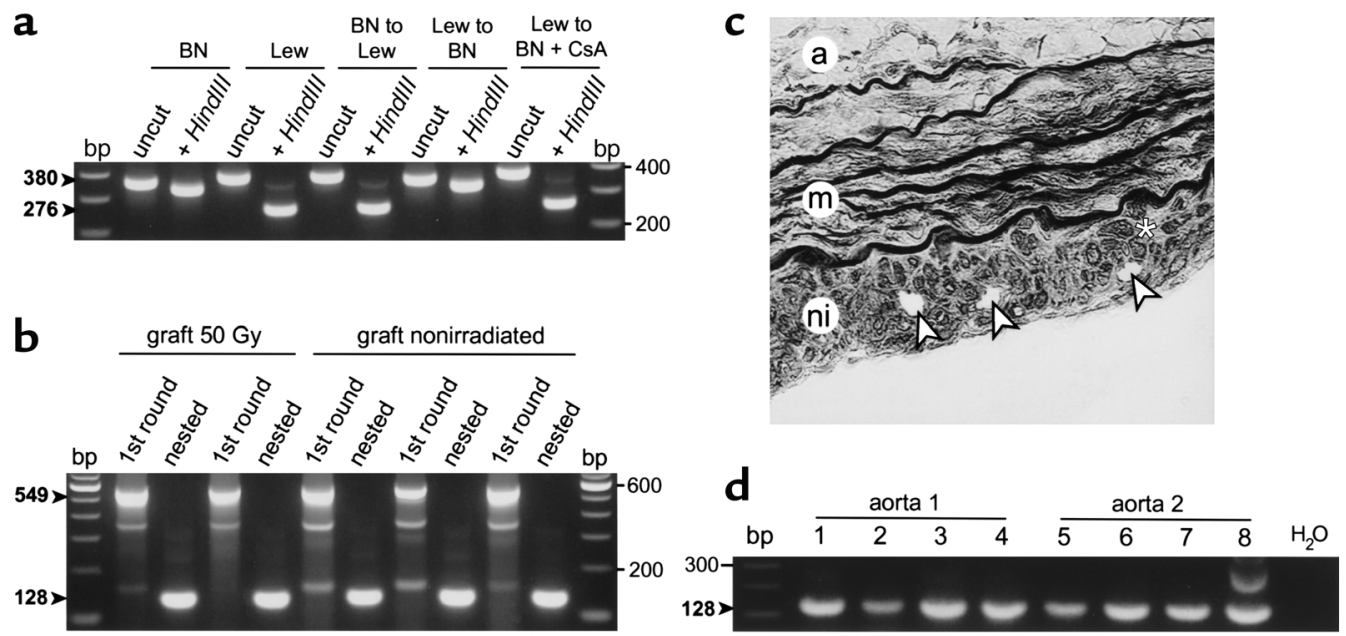

\footnotetext{
Figure 4

PCR analysis of 70- $\mu$ m-thick tissue samples, microdissected cell clusters, and microdissected single nuclei of $\alpha$-actin-positive neointimal VSM cells after allogeneic aorta transplantation. (a) Tap2 PCR analysis of $70-\mu m$-thick tissue samples from aortic allografts transplanted in the BN to Lew, Lew to BN, and Lew to BN + CsA combinations. Lew-derived DNA is cut after HindIII restriction, whereas BN-derived DNA remains uncut. Restriction analysis indicates recipient origin in untreated allografts. After CsA treatment, restriction analysis indicated donor origin. (b) HY PCR analysis of microdissected neointimal cell clusters from allografts transplanted in the female PVG to male AO strain combination. Grafts were $50 \mathrm{~Gy} \gamma$-irradiated prior to transplantation or left untreated. Representative results of first- and second-round PCR products (549 and $128 \mathrm{bp}$ ) of two irradiated and three untreated grafts are shown. All samples show the male-specific DNA fragments after first- and second-round PCR. (c) Micrograph (double staining for $\alpha$-actin and elastin) on an aortic allograft after isolation of single nuclei using a micromanipulator. Arrowheads indicate remaining gaps after isolation of nuclei of three separate $\alpha$-actin-positive neointimal cells. Note absence of VSM cells in the media. a, adventitia; $m$, media; ni, neointima. Asterisk shows an $\alpha$-actin-positive VSM cell. Original magnification: $\times 400$. (d) HY PCR performed on eight single nuclei microdissected from two aortic allografts transplanted from female PVG to male $\mathrm{AO}$ recipient rats, showing the male-specific (recipient-specific) 128-bp DNA fragment after nested PCR. bp, 100-bp ladder; $\mathrm{H}_{2} \mathrm{O}$, water control (i.e., no template DNA present in the PCR reaction mixture).
} 
a

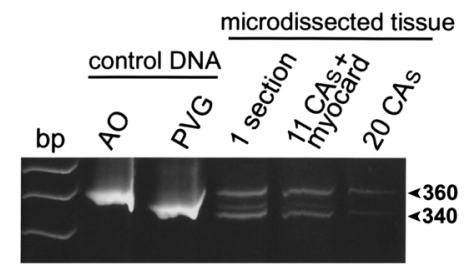

b

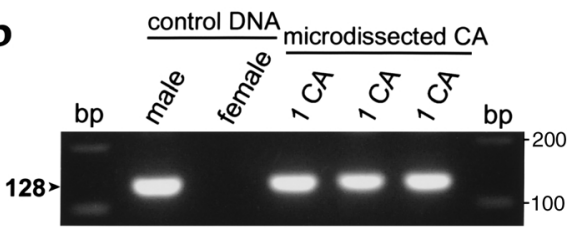

C

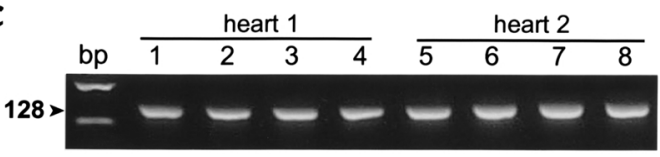

Figure 5

PCR analysis of microdissected pooled CAs (Tap2 PCR), and of single $C A s$ and single nuclei of $\alpha$-actin-positive neointimal cells (HY PCR). (a) PAGE after Tap2 PCR analysis of pooled microdissected CAs from a PVG cardiac allograft with severe TA. AO- and PVGderived DNA served as specificity controls. PCR analysis of one 7- $\mu \mathrm{m}$ tissue section showed presence of donor (PVG, $340 \mathrm{bp}$ ) as well as recipient (AO, 360 bp) DNA. Analysis of 11 pooled CAs including (donor-derived) myocardial tissue again showed presence of donoras well as recipient-derived DNA. Analysis of 20 pooled CAs without myocardial tissue resulted in presence of primarily recipient-derived DNA. (b) HY PCR analysis of three single CAs that were microdissected from three different female-derived PVG cardiac allografts transplanted into male $A O$ recipient rats. Female- and male-derived DNA from $A O$ rats served as specificity controls. All three single CAs showed the male-specific (recipient-specific) 128-bp DNA fragment after nested PCR analysis, indicating presence of recipient-derived cells. (c) HY PCR performed on eight single nuclei microdissected from two cardiac allografts showing the male-specific (recipient-specific) 128-bp DNA fragment.

be made by difference in size of the PCR products ( 340 and $360 \mathrm{bp}$, respectively). Analysis of one complete 7$\mu \mathrm{m}$ section of a cardiac allograft showed presence of donor-derived (PVG, $340 \mathrm{bp}$ ) as well as recipientderived (AO, $360 \mathrm{bp}$ ) DNA fragments (Figure 5a). Subsequent analysis of pooled microdissected CAs, including donor myocardial tissue, again showed presence of both donor- and recipient-derived DNA fragments. Finally, 20 CAs of one graft were microdissected without contamination with donor-derived myocardial tissue. Again, recipient-derived ( $360 \mathrm{bp}$ ), and now to a lesser extent donor-derived (340 bp), DNA fragments were present (Figure 5a). These results suggest that after cardiac allografting, neointimal tissue consists, at least in major part, of recipient-derived cells.

HY PCR analysis of microdissected neointimal aortic tissue and CAs. Since the sensitivity of the Tap2 PCR was not sufficient to analyze microdissected cell clusters ( $20-30$ cells) and single CAs, another, more sensitive,
PCR-based analysis was developed as described in detail elsewhere (32). This highly sensitive and specific nested PCR procedure enabled the identification at the single-cell level of a 128-bp Y chromosome-associated DNA sequence and thereby of the (male) origin of cells. Since aortic and cardiac allografting was performed not only between MHC-incompatible rat strains but in a female (donor) to male (recipient) combination as well, we could use this HY marker as an indicator for male cellular origin.

First, this PCR was applied to microdissected cell clusters derived from neointimal lesions in aortic allografts with or without $50 \mathrm{~Gy} \gamma$-irradiation transplanted from female PVG donor to male recipient rats. Three individual grafts of either group were studied, and of each graft five microdissected cell clusters were analyzed. HY PCR performed on microdissected cell clusters resulted in appearance of $Y$ chromosome-specific DNA fragments in the nonirradiated as well as the 50 Gy $\gamma$-irradiated aortic allografts (Figure 4b). Firstround PCR already resulted in detectable amounts of specific DNA fragments (549 bp). Additional nested PCR confirmed this observation by the amplification of a 128-bp DNA fragment. Subsequently, this PCR was applied to microdissected single CAs obtained from three cardiac allografts. Of either graft, four single CAs (with severe TA) were microdissected and analyzed individually for the presence of male-derived (recipient-derived) cells. All samples analyzed showed the male-specific DNA fragments after the first round, as well as after nested PCR. Representative results of the nested PCR performed on three individual CAs microdissected from three different grafts, as well as specificity controls (male- and female-derived DNA), are shown in Figure 5b. Results obtained with the HY-specific as well as with the Tap2 PCR thus indicate the presence of recipient-derived cells, both in microdissected neointimal cell clusters obtained from aortic allografts and in microdissected whole CAs showing severe TA. However, although neointimal tissue predominantly consists of $\alpha$-actin-positive VSM cells (Figures $1 \mathrm{c}$ and $3 \mathrm{f}$ ), neointimal lesions can also contain an appreciable number of recipient-derived infiltrating leukocytes, especially macrophages (43). The neointimal lesions present in aortic allografts in this study indeed contained considerable numbers of $\mathrm{ED}^{+}$macrophages (Figure 1d). Neointimal lesions in CAs appeared to contain few if any infiltrating inflammatory cells (Figure 3); however, one cannot exclude the possibility that such inflammatory cells were present. Since the HY PCR is sufficiently sensitive to detect male-derived cells on the single-cell level, false-positive results could be obtained by neointima-contaminating recipient-derived inflammatory cells.

HY PCR analysis of microdissected single VSM cell nuclei. To avoid contamination of the samples with neointima-infiltrating inflammatory cells, HY PCR analysis was performed on microdissected single nuclei from $\alpha$-actin-positive neointimal cells from aortic and car- 
diac allografts. $\alpha$-Actin staining ensured positive identification of neointimal VSM cells and prevented potential contamination of our samples with intimainfiltrating inflammatory cells.

Aortic allografts. Figure $4 c$ shows a representative micrograph of an aortic allograft with TA after isolation of three VSM cell nuclei. First, PCR analysis was performed on nuclei isolated from allografts exchanged between male rats for both donor and recipient. As now neointimal VSM cells, by definition, were of male origin, we could test the efficacy of the isolation procedure and subsequent PCR analysis. In total, 13 isolated nuclei from two grafts were analyzed, of which 12 (92.3\%) showed the Y chromosome-specific (male-specific) 128-bp DNA fragment (not shown). Subsequently, the same procedure was performed on nuclei isolated from female PVG grafts transplanted into male $\mathrm{AO}$ recipients. Three grafts were analyzed, and from each graft eight nuclei were isolated. PCR analysis revealed that $21 / 24(87.5 \%)$ of the samples contained DNA and, of these, 19/21 (90.5\%) displayed the male-specific 128-bp DNA fragment. These results indicate that at least $90 \%$ of $\alpha$-actin-positive VSM cells in transplant arteriosclerotic lesions after allogeneic aorta transplantation are of recipient origin.

Coronary arteries. Subsequently, this PCR was applied to single nuclei microdissected from CAs showing severe TA. Again, three grafts were analyzed and from each graft eight nuclei were isolated. After allogeneic cardiac transplantation, neointimal $\alpha$-actin-positive VSM cells are recipient-derived. Figures $4 d$ and $5 c$ show representative results of the HY PCR applied to microdissected single nuclei from aortic and cardiac allografts, respectively.

The nucleotide sequence of the 128-bp PCR products was determined to confirm the Y-chromosomal nature of the amplified material. The obtained sequences were compared with the sequence data available from EMBL/GenBank data libraries, accession no. X80155 (clone 9.1ES8). The sequence data of the PCR products were identical to the sequence data available from the database, indicating that the 128-bp DNA fragment belongs to the $\mathrm{Y}$ chromosome (not shown).

\section{Discussion}

CTD is the primary cause of allograft loss after the first perioperative year and is today's most important problem in clinical organ transplantation. The hallmark of CTD is development of TA; i.e., progressive intimal thickening (neointima formation) consisting of $\alpha$-actin-positive VSM cells intermingled with recipientderived mononuclear cells ( $T$ cells and macrophages) (2). Current thought on the process of TA holds that medial VSM cells of affected arteries migrate into the subendothelial space and start to proliferate, leading to vascular narrowing and occlusion $(2,9,10,44)$. In this paper, we analyzed whether neointimal VSM cells as well as ECs are truly donor-derived, using two transplant models (aorta and heart) in rats $(28,29)$. To address this question, donor and recipient MHC class I haplotype-specific immunohistochemistry and PCR analyses of DNA sequences allowing discrimination between donor and recipient origin were performed.

First we analyzed development of TA after transplantation of aortic grafts that were ex vivo 50 Gy $\gamma$-irradiated (to inhibit proliferation and migration of medial VSM cells) prior to transplantation. It has been shown that $\gamma$-irradiation of cultured VSM cells in vitro inhibits proliferation of these cells after stimulation (45). Three months after transplantation, irradiated grafts showed severe TA, similar to nonirradiated grafts, suggesting recipient origin of neointimal cells. Aziz et al. performed similar experiments using liquid nitrogen to destroy medial VSM cells in aortic allografts prior to transplantation. These frozen allografts showed TA to the same extent as unmodified grafts, also suggesting recipient origin of neointimal cells (22).

Subsequently, aorta recipients were treated with $5 \mathrm{mg} / \mathrm{kg}$ or $10 \mathrm{mg} / \mathrm{kg} \mathrm{CsA}$ for 28 days to study the effect of immunosuppressive treatment on the development of TA. CsA treatment completely blocked neointima formation and preserved the vascular media, confirming that development of TA is primarily alloimmune-mediated. Neointima formation is dependent on, and proportional to, the extent of medial VSM cell damage (46). By suppressing the alloimmune response by CsA treatment, no medial VSM cell (and possibly also no EC) damage occurs; thereby development of TA is prevented. However, Stoltenberg et al. showed that administration of the same amounts of CsA, resulting in similar 24-hour CsA trough levels, resulted in significant inhibition, but no prevention of neointima formation 3 and 6 months after aorta transplantation in the $\mathrm{A} \times \mathrm{Cgg} 35 \mathrm{Irish}(\mathrm{ACI})$ to Lew strain combination (33). Differences between the rat strains used and the follow-up period might explain the different results.

To confirm the origin (donor vs. recipient) of neointimal endothelial and VSM cells in rat aortic allografts displaying extensive TA, we first performed recipient MHC class I specific immunohistochemistry. Results indicate that ECs indeed are of recipient origin in nontreated and irradiated aortic allografts. CsA treatment prevented neointima formation, and MHC class I staining showed that ECs layering the internal elastic lamina are still of donor type and are not being replaced by recipient-derived ECs. In contrast to the aortic allografts, neointimal ECs are still of donor type in cardiac allografts showing severe TA 530 days after engraftment. Similar results were found by Hasegawa et al. (47), who showed that after MHCmismatched cardiac allografting in mice ECs in CAs with neointimal lesions are still of donor origin at 12 weeks after transplantation by using MHC class II-specific immunohistochemistry.

The origin of ECs (donor vs. recipient) after organ allografting has been debated since Woodruff (48) and Medawar (49) suggested that replacement of donor ECs with recipient ECs (graft adaptation) might be an 
important factor in establishing transplantation tolerance in long-term allograft survivors. Since then, several groups reported data supporting (11-16) and discounting $(17-20,24)$ repopulation of graft vessels by recipient-derived ECs after solid organ transplantation (kidney, heart, and lung) (reviewed in ref. 50). Taken together, results from literature and data presented in this paper suggest that EC replacement is not a general phenomenon after allogeneic organ transplantation. In the absence of immunosuppression, donor ECs become necrotic and disappear within 2 weeks after allogeneic aorta transplantation in rats $(21,24)$. This severe damage of donor ECs might explain the repopulation of the graft with recipient-derived endothelium. After cardiac transplantation following intrathymic immune modulation and short-term immunosuppression, remaining alloreactivity against graft endothelium as well as alloimmune-independent factors do not result in sufficient EC damage leading to EC replacement. Recently, we reported that after intrathymic immune modulation the intragraft cytokine profile in long-term allografts ( $>200$ days) has shifted from a Th1 type (high IL-2 and IFN- $\gamma$ ) toward a Th3 or Tr1 type (high IFN- $\gamma$, TGF- $\beta$, and IL-10; no IL-2) profile. This altered immune response might preserve graft endothelium, but it does not prevent the development of TA (30). Studying human kidney biopsies, Lagaaij et al. recently suggested a correlation between the degree of EC replacement by recipient-derived endothelium and the severity of vascular rejection (16). Replacement of donor endothelium by recipient-derived ECs seems to be related to graft dysfunction, rather than to graft function as suggested by Woodruff and Medawar (48, 49 ), and seems to play a role in endothelial repair processes upon (severe) vascular injury.

The origin of the neointimal VSM cells in the arteriosclerotic lesions still remains questionable. The original paradigm concerning the development of TA implies intimal hyperplasia to be derived from the donor media (8). This is supported by findings of Hruban et al., who showed donor origin of neointimal VSM cells in two patients using fluorescence in situ hybridization on tissue sections (20). However, data have also been reported indicating recipient origin of neointimal VSM cells in experimental transplant models (21-23). MHC class I haplotype-specific immunochemistry did not allow distinction between donor and recipient origin of neointimal VSM cells in our transplant models, since both neointimal and medial $\alpha$-actin-positive VSM cells do not express sufficient amounts of MHC class I antigens for detection. A similar lack of expression has been described for MHC class II antigens on neointimal VSM cells (47).

Therefore we addressed the question of whether neointimal VSM cells are truly graft-derived using two unrelated PCR-based analyses (Tap2 and HY) on aortic and cardiac allografts, enabling discrimination between donor and recipient-derived cells.

Using both types of PCR analysis on aortic allografts and microdissected CAs with severe TA, we found that at least a significant part of the cells in these tissues displays recipient-type DNA. Similar data were obtained for irradiated aortic allografts. However, neointimal lesions have been reported to contain an appreciable number of recipient-derived infiltrating leukocytes (43). Also, the aortic allografts analyzed in this study contained neointima-infiltrating mononuclear cells, consisting predominantly of $\mathrm{ED} 1^{+}$macrophages and some $\mathrm{T}$ cells. Such contaminating recipient-derived leukocytes can account for the recipient-specific signal in our analysis of aortic allografts and microdissected CAs, especially for the male-specific analysis, since the HY PCR is much more sensitive than the Tap2 PCR. Similar problems may also have influenced the results of Plissonnier et al. (21) and more recently Brazelton et al. (23) on the origin of VSM cells in vascular allografts. These groups used allospecific immunofluorescent staining of cell suspensions (21) and tissue sections (23) of aortic and femoral arterial allografts. Although their conclusion, that neointimal VSM cells are of recipient origin, in itself is probably correct, their type of analysis cannot distinguish between the infiltrating (recipientderived) leukocytes and neointimal VSM cells.

Since our male-specific nested HY PCR allows detection of male-derived cells at the single-cell level (32), we analyzed microdissected single nuclei of neointimal VSM cells. Nuclei were isolated from neointimal lesions of both aortic allografts and CAs with severe TA by positive selection ( $\alpha$-actin staining), thereby eliminating the risk of contaminating our samples with infiltrating recipient-derived mononuclear cells. HY PCR analysis of single nuclei of $\alpha$-actin-positive neointimal cells showed that at least $90 \%$ of these cells in neointimal lesions of both aortic allografts and CAs from cardiac allografts are of recipient origin.

Although Hasegawa et al. claim that VSM cells in neointimal lesions of CAs after cardiac transplantation in mice are probably still of donor origin at 12 weeks after transplantation, their type of analysis, MHC class II specific immunohistochemistry, does not allow determination of origin of neointimal VSM cells because of lack of MHC class II antigen expression on these neointimal VSM cells (47).

Since our data show recipient origin of neointimal VSM cells (aortic and cardiac allografts) and endothelium (aortic allografts), the question arises: what is the anatomical origin of these neointimal cells? Kouchi et al. demonstrated bloodstream origin of endothelial and $\alpha$-actin-positive smooth muscle cells present on Dacron grafts transplanted in dogs (51). Recently, recirculating bone marrow-derived $\mathrm{CD} 34^{+}$EC progenitor cells (EPCs) have been identified in the peripheral blood of humans $(52,53)$. The frequency of circulating EPCs increases in response to regional ischemia in both mice and rabbits. This increased frequency of circulating EPCs contributes to neovascularization of ischemic regions (54), indicating that EPCs are mobilized from the bone marrow into the circulation and subsequently "home" to sites needing neovascularization. Using bone 
marrow chimeric dogs, Shi et al. demonstrated donor (bone marrow) origin of ECs attached on implanted Dacron grafts, also indicating existence of circulating bone marrow-derived ECs (55). In another study, Bhattacharya et al. recently showed enhanced re-endothelialization of Dacron grafts after seeding with bone marrow-derived $\mathrm{CD} 34^{+}$cells prior to implantation (56). Taken together, these results suggest an important role for bone marrow-derived $\mathrm{CD} 34^{+}$progenitor cells as a source for ECs.

The anatomical source of the neointimal VSM cells is still unknown. One possibility might be ingrowth of medial VSM cells from the recipient side of anastomosis, as suggested by Aziz et al. (22). VSM cell destruction by freezing the recipient aortic ends at both sides near the anastomosis resulted in less pronounced intimal thickening compared with untreated aortic allografts. However, the frozen recipient aortic ends remained devoid of $\alpha$-actin-positive VSM cells during the observation period of 60 days. If the neointimal VSM cells originate from the recipient media, one should expect migration of $\alpha$-actin-positive VSM cells along the frozen aortic ends toward the mid-graft region. This was, however, not clear from the study by Aziz et al (22). A second possibility is transdifferentiation from ECs into $\alpha$-actin-positive VSM cells. Studying quail embryos, de Ruiter et al. showed transdifferentiation of embryonic ECs into $\alpha$-actin-expressing mesenchymal cells in vivo and in vitro (57).

The third possibility for the anatomical origin of neointimal VSM cells is the existence of VSM progenitor cells that differentiate into $\alpha$-actin-positive VSM cells. Circulating VSM progenitor cells, however, have not been identified so far. Bucala et al. reported the existence of a non-bone marrow-derived circulating cell population with fibroblast properties that specifically enters sites of tissue injury (58). In addition, Kouchi et al. described the presence of $\alpha$-actin-positive smooth muscle cells on Dacron grafts, which apparently originated from the bloodstream (51). Using whole vessel wall organ cultures, Slomp et al. showed migration of adventitial myofibroblasts to the luminal surface, where they transdifferentiated into endothelial-like cells as well as into a VSM cell phenotype in intimal thickening (59). These results suggest the existence of a myofibroblast cell lineage that can serve as an endothelial and smooth muscle stem cell population. In our aortic transplant model, sequential immunohistological analysis of developing TA at an early stage after transplantation indeed suggests a blood-borne influx of regenerating VSM cells (not shown).

In conclusion, in contrast to current thought about the process of TA, the $\alpha$-actin-positive VSM cells in the hyperplastic neointima in aortic and cardiac allografts are of recipient and not of donor origin. Neointimal ECs in aortic allografts are replaced by recipientderived endothelium, whereas in cardiac allografts neointimal ECs are not replaced and are still of donor origin. So, independent of EC replacement, donor VSM cells in the graft are replaced by VSM cells of recipient origin in these two transplant models.

We propose that the development of TA is an attempt to restore vascular function upon immunological injury (alloreactivity) and is essentially part of a normal healing process. Basically, as a result of the immunological injury, medial VSM cells disappear, leaving the elastin network as a scaffold allowing restoration of the vessel wall by recipient-derived cells. However, in TA this remodeling does not seem to stop, eventually leading to total occlusion of the vessels involved. According to this concept, at least two windows in time seem to exist that would allow therapeutic intervention to prevent the development of severe TA. The first is early after transplantation, when primary vascular graft damage through either ischemia or alloreactivity should be preventable. Perhaps current immunosuppressive therapies should even be intensified or adapted to suppress nonclinical rejection episodes causing vascular damage eventually leading to TA. The second window for intervention would be later, when TA starts to develop. Our data suggest that TA is the result of a repair process proceeding beyond the needs of functional repair. Future intervention strategies at this stage should aim at regaining proper control of this dysregulated process.

\section{Acknowledgments}

This study was supported by a research grant from the University Hospital Groningen (AZG) (Groningen, The Netherlands). We thank M.C. Harmsen from the Department of Medical Biology for providing the equipment for microdissection and R.A. Uges for performing CsA measurements. We thank B. Hellinga for assistance with preparing the photomicrographs.

\footnotetext{
1. Azuma, H., and Tilney, N.L. 1994. Chronic graft rejection. Curr. Opin. Immunol. 6:770-776.

2. Häyry, P., et al. 1993. Chronic allograft rejection. Immunol. Rev. 134:33-81.

3. Häyry, P., et al. 1997. Immunobiology and pathology of chronic rejection. Transplant. Proc. 29:77-78.

4. Sundaresan, S., Trulock, E.P., Mohanakumar, T., Cooper, J.D., and Patterson, G.A. 1995. Prevalence and outcome of bronchiolitis obliterans syndrome after lung transplantation. Washington University Lung Transplant Group. Ann. Thorac. Surg. 60:1341-1347.

5. Demetris, A., et al. 2000. Update of the international Banff schema for liver allograft rejection: working recommendations for the histopathologic staging and reporting of chronic rejection. Hepatology. 31:792-799.

6. Hosenpud, J.D., et al. 1998. The Registry of the International Society for Heart and Lung Transplantation. Fifteenth official report: 1998. J. Heart Lung Transplant. 17:656-668.

7. Costanzo, M.R., et al. 1998. Heart transplant coronary artery disease detected by coronary angiography: a multiinstitutional study of preoperative donor and recipient risk factors. J. Heart Lung Transplant. 17:744-753.

8. Häyry, P., et al. 1993. Pathophysiology of vascular wall changes in chronic allograft rejection. Transplant. Rev. 7:1-20.

9. Katoh, Y., and Periasamy, M. 1996. Growth and differentiation of smooth muscle cells during vascular development. Trends Cardiovasc. Med. 6:100-106.

10. Häyry, P. 1998. Chronic rejection: an update on the mechanism. Transplant. Proc. 30:3993-3995.

11. Williams, G.M., and Alvarez, C.A. 1969. Host repopulation of the endothelium in allografts of kidneys and aorta. Surg. Forum. 20:293-294.

12. Sinclair, R.A. 1972. Origin of endothelium in human renal allografts. Br. Med. J. 4:15-16.
} 
13. Williams, G.M., Krajewski, C.A., Dagher, F.J., Roth, J.A., and Santos, G.W. 1971. Host repopulation of endothelium. Transplant. Proc. 3:869-872.

14. Sedmak, D.D., Sharma, H.M., Czajka, C.M., and Ferguson, R.M. 1988. Recipient endothelialization of renal allografts. Transplantation. 46:907-910.

15. O'Connell, J.B., Renlund, D.G., Bristow, M.R., and Hammond, E. 1991. Detection of allograft endothelial cells of recipient origin following ABO-compatible, nonidentical cardiac transplantation. Transplantation. 51:438-442.

16. Lagaaij, E.L., et al. 2001. Endothelial cell chimerism after renal transplantation and vascular rejection. Lancet. 357:33-37.

17. Bieber, C.P., Stinson, E.B., Shumway, N.E., Payne, R., and Kosek, J. 1970. Cardiac transplantation in man. VII. Cardiac allograft pathology. Circulation. 41:753-772.

18. Bohle, A., and Fischbach, H. 1970. Further findings on adaptation of transplants of human kidneys. Virchows Arch. A Pathol. Pathol. Anat. 349:170-178.

19. Yousem, S.A., and Sonmez-Alpan, E. 1991. Use of biotinylated DNA probe specific for the human Y chromosome in the evaluation of the allograft lung. Chest. 99:275-279.

20. Hruban, R.H., et al. 1993. Fluorescence in situ hybridization for the Ychromosome can be used to detect cells of recipient origin in allografted hearts following cardiac transplantation. Am. J. Pathol. 142:975-980.

21. Plissonnier, D., et al. 1995. Sequential immunological targeting of experimental arterial allograft. Transplantation. 60:414-424.

22. Aziz, S., McDonald, T.O., and Gohra, H. 1995. Transplant arterial vasculopathy: evidence for a dual pattern of endothelial injury and the source of smooth muscle cells in lesions of intimal hyperplasia. J. Heart Lung Transplant. 14:S123-S136.

23. Brazelton, T.R., Adam, B., Shorthouse, R., and Morris, R.E. 1999. Chronic rejection: the result of uncontrolled remodelling of graft tissue by recipient mesenchymal cells? Data from two rodent models and the effects of immunosuppressive therapies. Inflamm. Res. 48:S134-S135

24. Bittmann, I., Petersen, P., Baretton, G.B., Land, W., and Löhrs, U. 1995 Evaluation of chronic allograft reaction in kidneys by interphase cytogenetics with centromere-specific DNA probes and immunocytochemistry with regard to distribution of donor and recipient cells. Transplant. Proc. 27:2033-2035.

25. van der Lei, B., et al. 1985. Regeneration of the arterial wall in microporous, compliant, biodegradable vascular grafts after implantation into the rat abdominal aorta. Cell Tissue Res. 242:569-578.

26. van der Lei, B., Wildevuur, C.R.H., and Nieuwenhuis, P. 1986. Compliance and biodegradation of vascular grafts stimulate the regeneration of elastic laminae in neoarterial tissue: an experimental study in rats. Surgery. 99:45-52.

27. Nieuwenhuis, P., Hillebrands, J.L., and Rozing, J. 2000. Chronic allograft rejection associated vasculopathy and synthetic biodegradable vascular grafts: a lesson to learn? Crit. Rev. Immunol. 20:85-88.

28. Mennander, A., et al. 1991. Chronic rejection in rat aortic allografts: an experimental model for transplant arteriosclerosis. Arterioscler. Thromb. 11:671-680.

29. Klatter, F.A., et al. 1995. Simultaneous transplantation and intrathymic tolerance induction: a method with clinical potential. Transplantation. 60:1208-1210.

30. Hillebrands, J.L., et al. 2001. Intrathymic immune modulation prevents acute rejection but not the development of graft arteriosclerosis (chronic rejection). Transplantation. 71:914-924.

31. Joly, E., et al. 1994. The distribution of Tap2 alleles among laboratory rat RT1 haplotypes. Immunogenetics. 40:45-53.

32. Hillebrands, J.L., et al. 2000. Recipient origin of neointimal vascular smooth muscle cells in cardiac allografts with transplant arteriosclerosis. J. Heart Lung Transplant. 19:1183-1192.

33. Stoltenberg, R.L., et al. 1995. Inhibition of intimal hyperplasia in rat aortic allografts with cyclosporine. Transplantation. 60:993-998.

34. Skalli, O., et al. 1986. A monoclonal antibody against alpha-smooth muscle actin: a new probe for smooth muscle differentiation. J. Cell Biol. 103:2787-2796.

35. Schürch, W., Skalli, O., Seemayer, T.A., and Gabbiani, G. 1987. Intermediate filament proteins and actin isoforms as markers for soft tissue tumor differentiation and origin. Am. J. Pathol. 128:91-103.

36. Fukumoto, T., McMaster, W.R., and Williams, A.F. 1982. Mouse mon- oclonal antibodies against rat major histocompatibility antigens. Eur J. Immunol. 12:237-243.

37. Jefferies, W.A., Green, J.R., and Williams, A.F. 1985. Authentic T helper CD4 (W3/25) antigen on rat peritoneal macrophages. J. Exp. Med. 162:117-127.

38. Stet, R.J.M., et al. 1987. U9F4: a monoclonal antibody recognizing a rat polymorphic class I determinant. Transplant. Proc. 19:3004-3005.

39. Duyvestijn, A.M., et al. 1992. Antibodies defining rat endothelial cells: RECA-1, a pan-endothelial cell-specific monoclonal antibody. Lab. Invest. 66:459-466.

40. Dijkstra, C.D., Dopp, E.A., Joling, P., and Kraal, G. 1985. The heterogeneity of mononuclear phagocytes in lymphoid organs: distinct macrophage subpopulations in the rat recognized by monoclonal antibodies ED1, ED2 and ED3. Immunology. 54:589-599.

41. Essers, J., de Stoppelaar, J.M., and Hoebee, B. 1995. A new rat repetitive DNA family shows preferential localization on chromosome 3,12 and $\mathrm{Y}$ after fluorescence in situ hybridization and contains a subfamily which is Y chromosome specific. Cytogenet. Cell Genet. 69:246-252.

42. Hillebrands, J.L., Klatter, F.A., Bruggeman, C.A., and Rozing, J. 2001 Development of transplant arteriosclerosis after allogeneic aorta transplantation in the rat: influence of recipient genotype. Transplant. Proc. 33:324-325.

43. Demetris, A.J., Zerbe, T., and Banner, B. 1989. Morphology of solid organ allograft arteriopathy: identification of proliferating intimal cell populations. Transplant. Proc. 21:3667-3669.

44. Lemström, K., Koskinen, P., and Häyry, P. 1995. Molecular mechanisms of chronic renal allograft rejection. Kidney Int. 48:S2-S10.

45. Heckenkamp, J., Leszczynski, D., Schiereck, J., Kung, J., and LaMuraglia, G.M. 1999. Different effects of photodynamic therapy and $\gamma$-irradiation on vascular smooth muscle cells and matrix. Arterioscler. Thromb. Vasc. Biol. 19:2154-2161.

46. Légaré, J.F., Issekutz, T., Lee, T.D.G., and Hirsch, G. 2000. CD8+ T lymphocytes mediate destruction of the vascular media in a model of chronic rejection. Am. J. Pathol. 157:859-865.

47. Hasegawa, S., Becker, G., Nagano, H., Libby, P., and Mitchell, R.N. 1998. Pattern of graft- and host-specific MHC class II expression in long-term murine cardiac allografts. Origin of inflammatory vascular wall cells. Am. J. Pathol. 153:69-79.

48. Woodruff, M. 1959. Biological problems in grafting. In Biological problems of grafting. A symposium sponsored by the Commission Administrative du Patrimaine Universitaire de Liège and the Council for International Organizations of Medical Sciences, 18-21 March 1959. F. Albert and P.B. Medawar, editors. Blackwell Scientific. Oxford, United Kingdom. p. 83

49. Medawar, P.B. 1965. Transplantation of tissues and organs: introduction. Br. Med. Bull. 21:97-99.

50. Hillebrands, J.L., Nieuwenhuis, P., and Rozing, J. 2000. The origin of vascular smooth muscle cells and endothelium in transplant arteriosclerosis. Graft. 3:205-211.

51. Kouchi, Y., et al. 1998. Apparent blood stream origin of endothelial and smooth muscle cells in the neointima of long, impervious carotidfemoral grafts in the dog. Ann. Vasc. Surg. 12:46-54.

52. Asahara, T., et al. 1997. Isolation of putative progenitor endothelial cells for angiogenesis. Science. 275:964-967.

53. Asahara, T., et al. 1999. Bone marrow origin of endothelial progenitor cells responsible for postnatal vasculogenesis in physiological and pathological neovascularization. Circ. Res. 85:221-228.

54. Takahashi, T., et al. 1999. Ischemia- and cytokine-induced mobilization of of bone-marrow derived endothelial progenitor cells for neovascularization. Nat. Med. 5:434-438.

55. Shi, Q., et al. 1998. Evidence for circulating bone marrow-derived endothelial cells. Blood. 92:362-367.

56. Bhattacharya, V., et al. 2000. Enhanced endothelialization and microvessel formation in polyester grafts seeded with $\mathrm{CD} 34^{+}$bone marrow cells. Blood. 95:581-585.

57. de Ruiter, M.C., et al. 1997. Embryonic endothelial cells transdifferentiate into mesenchymal cells expressing smooth muscle actins in vivo and in vitro. Circ. Res. 80:444-451.

58. Bucala, R., Spiegel, L.A., Chesney, J., Hogan, M., and Cerami, A. 1994. Circulating fibrocytes define a new leukocyte subpopulation that mediates tissue repair. Mol. Med. 1:71-81.

59. Slomp, J., et al. 1996. Nature and origin of the neointima in whole vessel wall organ culture of the human saphenous vein. Virchows Arch. 428:59-67. 